\title{
Oligodendrocyte Myelin Glycoprotein Does Not Influence Node of Ranvier Structure or Assembly
}

\author{
Kae-Jiun Chang, ${ }^{1 \star}$ Keiichiro Susuki, ${ }^{2 \star}$ Maria T. Dours-Zimmermann, ${ }^{3}$ Dieter R. Zimmermann, ${ }^{3}$ \\ and Matthew N. Rasband ${ }^{1,2}$ \\ ${ }^{1}$ Program in Developmental Biology and ${ }^{2}$ Department of Neuroscience, Baylor College of Medicine, Houston, Texas 77030, and ${ }^{3}$ Institute of Surgical \\ Pathology, University Hospital Zurich, CH-8091 Zurich, Switzerland
}

Oligodendrocyte myelin glycoprotein (OMgp) is expressed by both neurons and oligodendrocytes in the CNS. It has been implicated in growth cone collapse and neurite outgrowth inhibition by signaling through the Nogo receptor and paired Ig-like receptor B (PirB). OMgp was also reported to be an extracellular matrix (ECM) protein surrounding CNS nodes of Ranvier and proposed to function as (1) an inhibitor of nodal collateral sprouting and (2) an important contributor to proper nodal and paranodal architecture. However, we show here that the anti-OMgp antiserum used in previous studies to define the functions of OMgp at nodes is not specific. Among all reported nodal ECM components, the antiserum exhibited strong cross-reactivity against versican V2 isoform, a chondroitin sulfate proteoglycan. Furthermore, the OMgp antiserum labeled OMgp-null nodes, but not nodes from versican V2-deficient mice, and preadsorption of the OMgp antiserum with recombinant versican V2 blocked nodal labeling. Analysis of CNS nodes in OMgp-null mice failed to reveal any nodal or paranodal defects, or increased nodal collateral sprouting, indicating that OMgp does not participate in CNS node of Ranvier assembly or maintenance. We successfully identified a highly specific anti-0Mgp antibody and observed 0Mgp staining in white matter only after initiation of myelination. OMgp immunoreactivity decorated the surface of mature myelinated axons, but was excluded from compact myelin and nodes. Together, our results strongly argue against the nodal localization of OMgp and its proposed functions at nodes, and reveal OMgp's authentic localization relative to nodes and myelin.

\section{Introduction}

Nodes of Ranvier are highly enriched in ion channels that play essential roles in saltatory conduction. Specific cell adhesion molecules and cytoskeletal scaffolds are also clustered at nodes and establish and/or maintain the proper function and architecture of nodes (Poliak and Peles, 2003; Salzer, 2003; Susuki and Rasband, 2008). In addition, a specialized ECM is assembled around nodes. By immunostaining, several CNS nodal ECM components have been identified: three chondroitin sulfate proteoglycans (brevican, phosphacan, and versican V2), brain link protein 1, tenascin-R, and OMgp (Bartsch et al., 1993; Xiao et al., 1997; Oohashi et al., 2002; Huang et al., 2005; Hedstrom et al., 2007). CNS nodal ECM components have been proposed to (1) contribute to the extracellular pool of sodium ions in the perinodal space, (2) inhibit axonal sprouting at nodes, and (3) contribute to node formation (Kaplan et al., 1997; Oohashi et al., 2002; Huang et al., 2005; Susuki and Rasband, 2008; Bekku et al., 2010).

Received April 2, 2010; revised Aug. 23, 2010; accepted Sept. 12, 2010.

This work was supported by National Institutes of Health Grants NS044916 and NS069688 (M.N.R.), the Swiss National Science Foundation (D.R.Z.), and the Velux Foundation (D.R.Z.). M.N.R. is a Harry Weaver Neuroscience Scholar of the National Multiple Sclerosis Society. We thank Dr. Sha Mi for generously providing the OMgp-null mice, Dr. Amyn Habib for the rabbit anti-OMgp antiserum, and Dr. Zhigang He for the mouse OMgp cDNA. We thank Debra Townley (Integrated Microscopy Core, Baylor College of Medicine) for technical assistance.

${ }^{*}$ K.-J.C. and K.S. contributed equally to this work.

Correspondence should be addressed to Dr. Matthew N. Rasband, Department of Neuroscience, Baylor College of Medicine, One Baylor Plaza, Houston, TX 77030. E-mail: Rasband@bcm.edu.

DOI:10.1523/JNEUROSCI.1698-10.2010

Copyright $\odot 2010$ the authors $\quad 0270-6474 / 10 / 3014476-06 \$ 15.00 / 0$
Among the nodal ECM components, OMgp is a Nogo receptor and PirB ligand, and their interactions mediate neurite outgrowth inhibition (Vourc'h and Andres, 2004; Atwal et al., 2008; Giger et al., 2008). OMgp was first identified and purified from human CNS white matter by its peanut agglutinin (PNA)binding property (Mikol and Stefansson, 1988). Although it can be a glycosylphosphatidylinositol (GPI)-anchored protein, OMgp is also found without its GPI moiety in brain homogenates and oligodendrocyte-conditioned medium (Mikol and Stefansson, 1988; Nie et al., 2006), suggesting that OMgp can be released from the cell surface. OMgp localization was first described in human CNS myelin and on the surface of cultured ovine oligodendrocytes (Mikol and Stefansson, 1988). Later studies using a rabbit anti-human OMgp antiserum reported OMgp localization in the outer edges of PNS myelin sheaths around the paranodes (Apostolski et al., 1994), and at both PNS and CNS nodes of Ranvier (Huang et al., 2005; Nie et al., 2006).

OMgp-null mice were reported to show strain-specific improvements in axon regeneration (Ji et al., 2008), more frequent axonal sprouting at nodes, disturbed paranodes, and wider nodal gaps (Huang et al., 2005).

Given the proposed role for OMgp in CNS node of Ranvier function and assembly, we sought to determine the molecular mechanisms whereby OMgp performs its functions. However, we found the rabbit anti-OMgp antiserum used in previous studies showing nodal localization (Huang et al., 2005; Nie et al., 2006) is not specific to OMgp. Instead, it cross-reacts with versican V2, which is responsible for the nodal staining. Immunostain- 
A
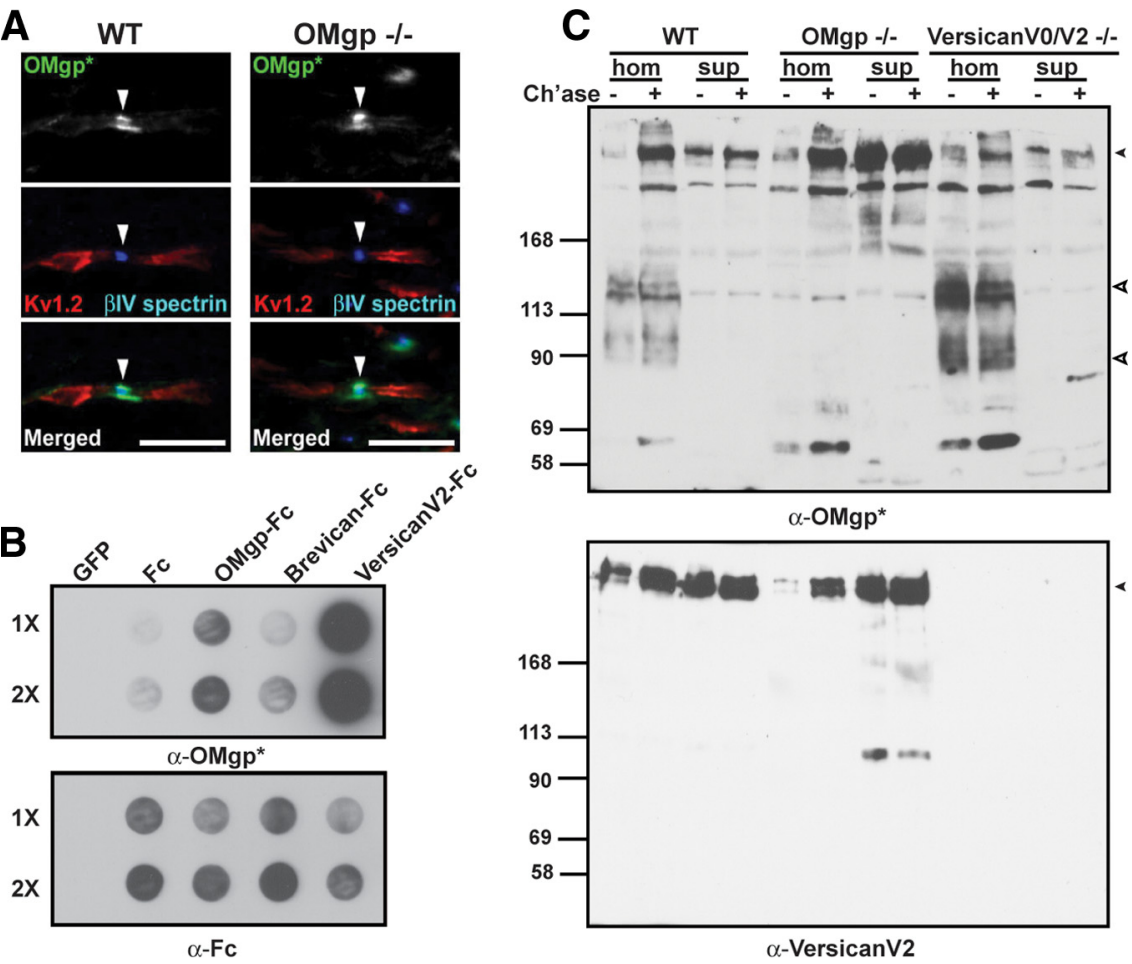

Figure 1. $\quad \alpha-0 \mathrm{Mgp}^{*}$ is not specific to OMgp and cross-reacts with versican V2. A, Spinal cord sections from wild-type and OMgp-null mice immunostained with $\alpha-0 \mathrm{Mgp}^{*}$ (green), anti- $\beta \mathrm{IV}$ spectrin (blue), and anti-Kv1.2 (red). Arrowheads indicate nodes of Ranvier. Scale bars, $10 \mu \mathrm{m} . \boldsymbol{B}$, Media collected from COS-7 cell cultures expressing palmitoylated EGFP (GFP), Fc, OMgp-Fc, brevican-Fc, and versican V2-Fc were applied to nitrocellulose membranes onefold $(1 \times)$ or twofold $(2 \times)$ concentrated and probed with $\alpha-0 \mathrm{Mgp}^{*}$ or anti-human $\mathrm{Fc}$. C, Immunoblotting of brain membrane homogenates (hom; $75 \mu \mathrm{g}$ ) and cytosolic fractions (sup; $20 \mu \mathrm{g}$ ) made from WT, 0Mgp-null, and versican V0/N2-null brains with or without chondroitinase $\mathrm{ABC}$ treatment (Ch'ase $+/-$ ). Blots were probed with $\alpha-0 \mathrm{Mgp} *$ or antiversican V2 antibodies. The top arrowhead indicates the position of versican V2, and the bottom two open arrowheads indicate $0 \mathrm{Mgp}$ with (upper) and without (lower) the GPI moiety (Mikol and Stefansson, 1988).

ing with a specific anti-OMgp antibody pinpointed OMgp around compact myelin, but not at nodes. Our analysis of OMgp-null mice showed normal paranodal junctions and nodal architecture. Therefore, OMgp is not accumulated at the nodal ECM and does not play the essential role in node formation and stabilization as previously proposed (Huang et al., 2005; Nie et al., 2006).

\section{Materials and Methods}

Animals. OMgp-null mice were generously provided by Dr. Sha Mi (Department of Discovery Biology, Biogen Idec) (Ji et al., 2008). Versican V0/ V2-null mice were described previously (Dours-Zimmermann et al., 2009). Wild-type ICR and C57BL/6 mice were purchased from Charles River.

Antibodies. The following primary antibodies were used: rabbit antiOMgp antiserum, kindly provided by Dr. Amyn Habib (Department of Neurology, University of Texas Southwestern Medical Center, Dallas, TX) $\left(\alpha\right.$-OMgp $\left.{ }^{\star}\right)$ (Habib et al., 1998; Huang et al., 2005; Nie et al., 2006); mouse anti-OMgp monoclonal clone 1A8 (H00004974-M06, Abnova); rabbit Prestige anti-OMgp (HPA012693, Sigma); goat anti-OMgp (AF1674, R\&D Systems); mouse anti-Kv1.2 (K14/16, UC Davis/NIH NeuroMab Facility); chicken anti- $\beta$ IV spectrin antibody, generated and affinity purified against the same peptide as previously reported for the rabbit anti- $\beta$ IV spectrin SD antibody (Berghs et al., 2000); rabbit anti-versican V0/V2 (Dours-Zimmermann et al., 2009); mouse anti-Caspr (K65/35, NeuroMab); mouse anti-myelin basic protein (MBP) (Covance); and rabbit anti-neurofilament $M$ (Millipore). Horseradish peroxidase (HRP)-conjugated goat anti-human Fc was from Jackson ImmunoResearch Laboratories. HRP-conjugated donkey anti-goat IgG, goat anti-rabbit IgG, and goat anti-mouse IgG were from MP Biomedicals. Fluorescent dye-conjugated secondary antibodies were purchased from Invitrogen.
Fc fusion proteins. The cDNAs corresponding to mouse OMgp (amino acids 25-417, NP_062282.1), rat brevican (amino acids 25883, AAA87847.1), and human versican V2 (amino acids 21-1642, AAA67565.1) were cloned into pSX-Fc (Eshed et al., 2007) in frame to the signal peptide and human IgG1 Fc. The pSX-Fc plasmid was kindly provided by Drs. E. Peles and Y. Eshed (Weizmann Institute of Science, Rehovot, Israel). The Fc fusion DNA constructs were transfected into COS-7 cells with Lipofectamine 2000 (Invitrogen) according to the manufacturer's instructions. The media were changed to VP-SFM (Invitrogen) containing $2 \times$ GlutaMAX-I. The media containing Fc fusions were harvested by centrifuging at $3000 \times g$ for 3 min and collecting the supernatants.

Immunostaining. Immunostaining of optic and sciatic nerves and spinal cords was performed as described previously (Rasband et al., 1999; Schafer et al., 2004). For analysis of node organization, the gap distance between a pair of Caspr-labeled paranodes and the width of Caspr staining were measured with AxioVision (Carl Zeiss) as the nodal length and axon diameter, respectively (wild-type, $n=423$; OMgpnull, $n=423$ ). Statistical analysis was performed using the Student's $t$ test, and errors indicated are \pm SEM.

Dot blotting and Western blotting. Brain membrane homogenates were prepared as described previously (Schafer et al., 2004). The brain cytosolic fractions were the supernatants collected after the second centrifugation step. Nerve extracts were prepared by collecting supernatants from nerves sonicated in homogenizing buffer on ice, and centrifuged at $600 \times g$ for $10 \mathrm{~min}$. Immunoblotting was performed as described previously (Schafer et al., 2004). Before electrophoresis, chondroitin sulfate digestion of brain membrane homogenates and cytosolic fractions was performed by incubating samples in $50 \mathrm{~mm}$ Tris- $\mathrm{HCl}, \mathrm{pH} 8.3,60 \mathrm{~mm}$ sodium acetate, $\mathrm{pH} 8,10 \mathrm{~mm}$ EDTA, $0.02 \%$ BSA $(\mathrm{w} / \mathrm{v})$, and $0.4-0.67 \mathrm{U} / \mathrm{ml}$ chondroitinase ABC (Sigma) at $37^{\circ} \mathrm{C}$ for $16 \mathrm{~h}$.

Immunoadsorption. Fc fusion proteins in the collected media were applied to nitrocellulose membranes by dot blot. The regions of the membrane with Fc fusion proteins were cut, put in $1.5 \mathrm{ml}$ microcentrifuge tubes, and washed with $0.1 \mathrm{~m}$ phosphate buffer, $\mathrm{pH}$ 7.4, containing $0.3 \%$ Triton X-100 and $10 \%$ goat serum (PBTGS). The primary antibodies diluted in PBTGS were incubated with the membrane in the tubes at $4^{\circ} \mathrm{C}$ overnight and then applied to tissue sections for immunostaining.

Rotarod. Mice were conditioned on the rotating rod (Ugo Basile) at 4 $\mathrm{rpm}$ for $5 \mathrm{~min}$. Mice then received a $1 \mathrm{~h}$ break. Mice were then tested for latency to fall in three trials by placing them on the rotating rod, which accelerated from 4 to $40 \mathrm{rpm}$ in $5 \mathrm{~min}$. Each trial was separated by a 30 min break, and latencies to fall were averaged across all trials.

Electron microscopy. One-hundred-day-old wild-type (WT) $(n=3)$ and OMgp knock-out $(n=3)$ mice were anesthetized with ketamine $(80$ $\mathrm{mg} / \mathrm{kg})$ and xylazine $(16 \mathrm{mg} / \mathrm{kg})$ by intraperitoneal injection. Then the animals were perfused with $2.5 \%$ glutaraldehyde and $2.0 \%$ paraformaldehyde in $0.1 \mathrm{M}$ cacodylate buffer, $\mathrm{pH}$ 7.4. Optic nerves were dissected out and postfixed in the same fixative for an additional $3 \mathrm{~h}$. Then, the nerves were postfixed in $1 \%$ osmium tetroxide solution in $0.1 \mathrm{~m}$ cacodylate buffer, $\mathrm{pH} 7.4$, for $2 \mathrm{~h}$. After washing, nerves were dehydrated through a graded ethanol series and embedded in low-viscosity resin (Electron Microscopy Sciences). Tissues were en bloc stained for $1 \mathrm{~h}$ in saturated uranyl acetate plus 50\% ethanol during dehydration. The sectioning and electron microscopy was performed in the Baylor College of Medicine Integrated Microscopy Core (Director: Dr. Michael A. Mancini). 


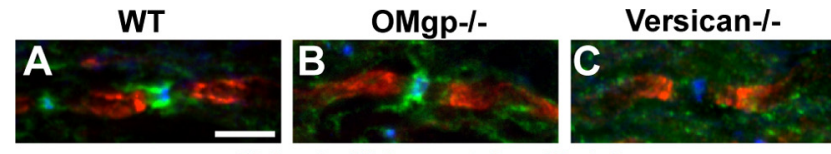

OMgp* $^{*}$ IV spectrin Kv1.2
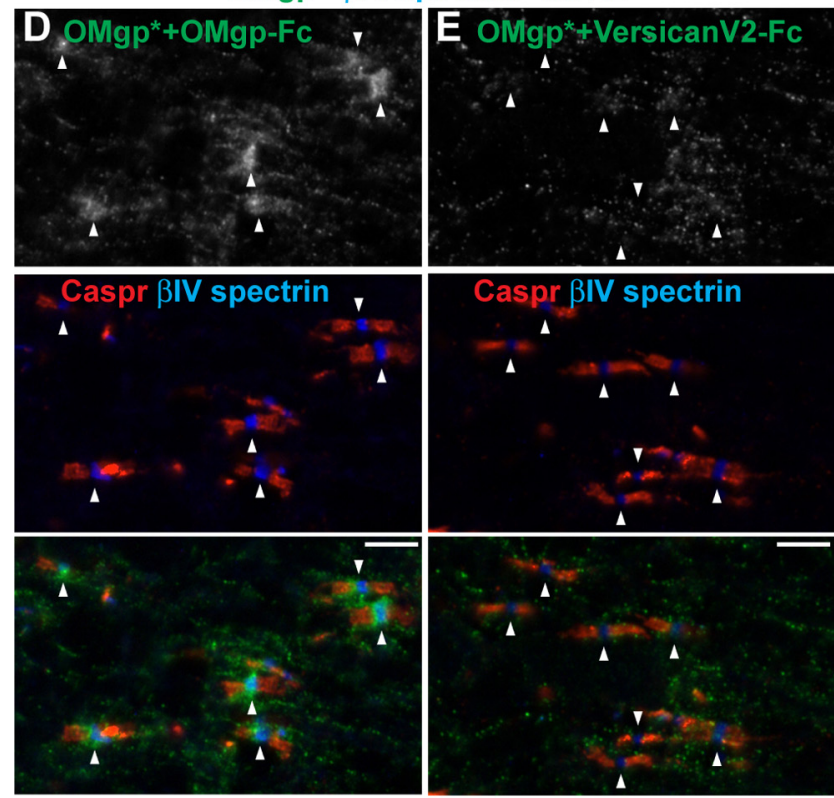

$\mathbf{F}$
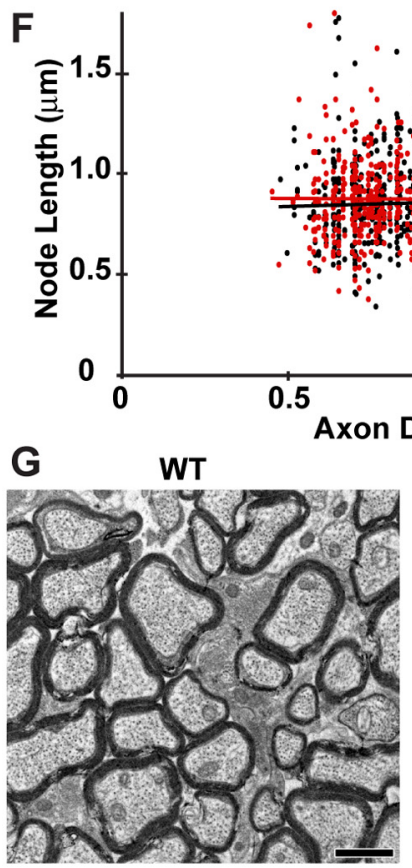

1.0

1.0

1.5
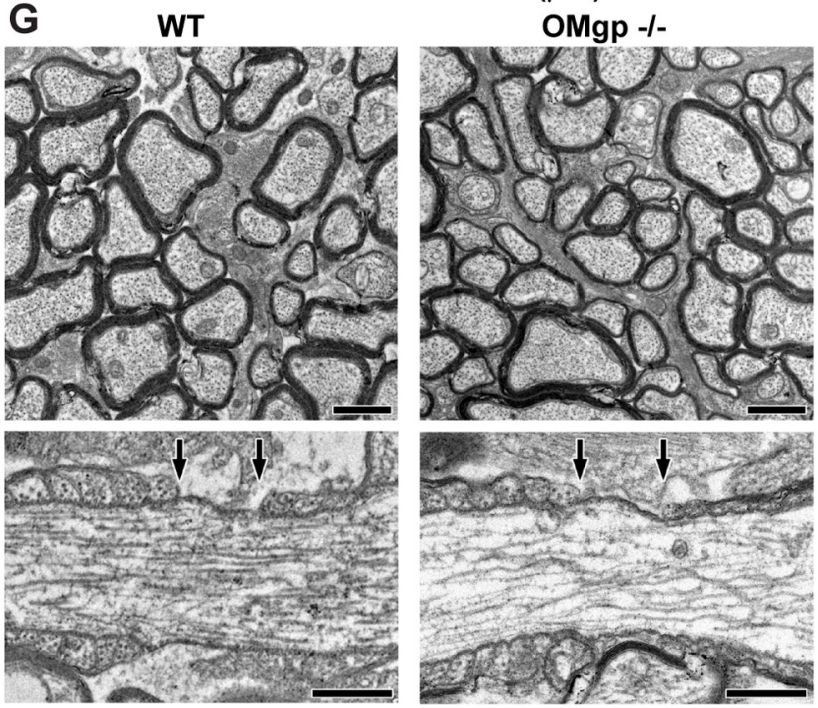

Figure 2. $\alpha-0 \mathrm{Mgp}^{*}$ detected versican V2 at CNS nodes of Ranvier. A-C, Optic nerve sections of WT, OMgp-null, and versican V0/V2-null mice stained with $\alpha$-0Mgp* (green), anti- $\beta$ IV spectrin (blue), and anti-Kv1.2 (red). Scale bar, $5 \mu \mathrm{m} . \boldsymbol{D}, \boldsymbol{E}, \alpha-0 \mathrm{Mgp}{ }^{*}$ was preadsorbed with 0 Mgp- $\mathrm{Fc}(\boldsymbol{D})$ or versican V2-Fc $(\boldsymbol{E})$ before being incubated with WT spinal cord sections. Arrowheads indicate nodes of Ranvier. Scale bars, $5 \mu \mathrm{m}$. $\boldsymbol{F}$, Node length plotted as a function of axon diameter in WT and OMgp-null optic nerves. $\boldsymbol{G}$, Electron micrographs of optic nerves from 100-d-old wild-type and 0Mgp null (-/-) mice. Top panels show cross sections of myelinated
Longitudinal and transverse thin sections of $\sim 70 \mathrm{~nm}$ were obtained using an RMC MT6000-XL ultramicrotome and a Diatome Ultra45 diamond knife, and collected on 150 hex-mesh copper grids. The dried sections were counterstained with Reynold's lead citrate for 4 min after microtomy. Sections were observed using a transmission electron microscope (H7500, Hitachi). Images were obtained and measurements were performed using a Gatan US1000 digital camera and Digital Micrograph v1.82.366 software.

\section{Results}

Rabbit anti-OMgp antiserum labels CNS nodes in OMgp-null mice and cross-reacts with versican $\mathrm{V} 2$

While investigating the functional role of OMgp in the CNS nodal ECM, we unexpectedly found that the rabbit anti-human OMgp antiserum (referred to hereafter as $\alpha$-OMgp ${ }^{\star}$ ) used in previous studies (Huang et al., 2005; Nie et al., 2006) stained strongly the nodes of Ranvier in both wild-type and OMgp-null spinal cords (Fig. $1 A$ ) and optic nerves (Fig. 2A,B). Thus, the nodal signal by this antiserum cannot be solely attributed to OMgp.

To determine whether this antiserum cross-reacts with other nodal ECM components such as versican V2 and/or brevican, we generated recombinant OMgp-Fc, versican V2-Fc, and brevican-Fc fusion proteins in COS-7 cells. These fusion proteins were subjected to immunoblotting using $\alpha$-OMgp ${ }^{*}$. As shown in Figure $1 B$, although $\alpha$-OMgp ${ }^{\star}$ detected OMgp-Fc, versican V2-Fc was detected much more strongly.

To further confirm the cross-reactivity against versican, we analyzed brain homogenates from wild-type, OMgp-null, and versican V0/V2-null mice. $\alpha$-OMgp ${ }^{\star}$ detected not only OMgp in the brain membrane homogenates prepared from the wild-type and versican V0/V2-null brains (Fig. 1C), but also versican V2 in the membrane homogenates and cytosolic fractions from wild-type and OMgpnull preparations (Fig. 1C). The extracellular versican in the membrane homogenates is modified with chondroitin sulfate side chains (Yamaguchi, 2000; Zimmermann and Dours-Zimmermann, 2008), and removal of these side chains is required for the bulk of versican to enter the SDS-PAGE gels (Schmalfeldt et al., 1998) (Fig. 1C). At the mobility similar to that of versican V2, only weak background signals that were insensitive to chondroitin sulfate digestion were detected in the versican V0/V2-null preparations by $\alpha$-OMgp ${ }^{*}$ (Fig. $1 C)$. These observations indicate that the $\alpha-\mathrm{OMgp}^{\star}$ antiserum used in the previous studies is not specific to OMgp, but instead strongly cross-reacts with versican $\mathrm{V} 2$.

\section{$\alpha-\mathrm{OMgp}^{\star}$ antiserum detects versican $\mathrm{V} 2$ at $\mathrm{CNS}$ nodes} of Ranvier

To test whether the nodal $\alpha$-OMgp ${ }^{\star}$ staining is due to its crossreactivity with versican $\mathrm{V} 2$, we immunostained versican V0/V2null tissues. We found that $\alpha$-OMgp ${ }^{*}$ labeled wild-type and OMgp-null nodes (Fig. $2 A, B$ ), but no staining was observed at versican V0/V2-null nodes (Fig. 2C), strongly suggesting that versican V2, but not OMgp, is detected by $\alpha$-OMgp ${ }^{*}$ at CNS nodes. To exclude the possibility that the presence of OMgp at nodes requires versican $\mathrm{V} 2$, we stained the wild-type spinal cord with $\alpha$-OMgp ${ }^{*}$ preadsorbed with OMgp-Fc or versican V2-Fc. While $\alpha$-OMgp ${ }^{*}$ preadsorbed with OMgp-Fc still labeled nodes (Fig. $2 \mathrm{D}), \alpha$-OMgp ${ }^{\star}$ preadsorbed with versican $\mathrm{V} 2$-Fc did not label nodes

axons in the optic nerves. Lower panels show single nodes of Ranvier from longitudinal sections of optic nerves. The nodal gap is defined by the two arrows above each axon. Scale bars: top, 1 $\mu \mathrm{m}$; bottom, $0.5 \mu \mathrm{m}$. 
A
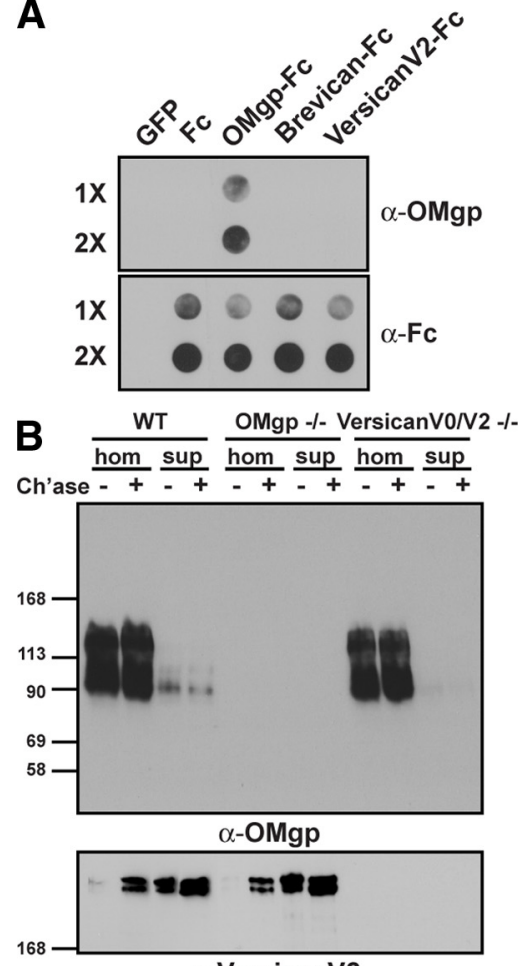

$\alpha$-VersicanV2

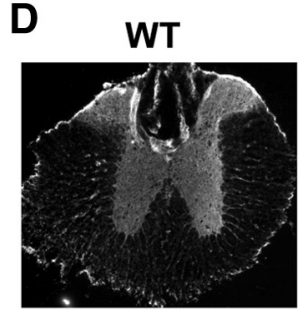

E
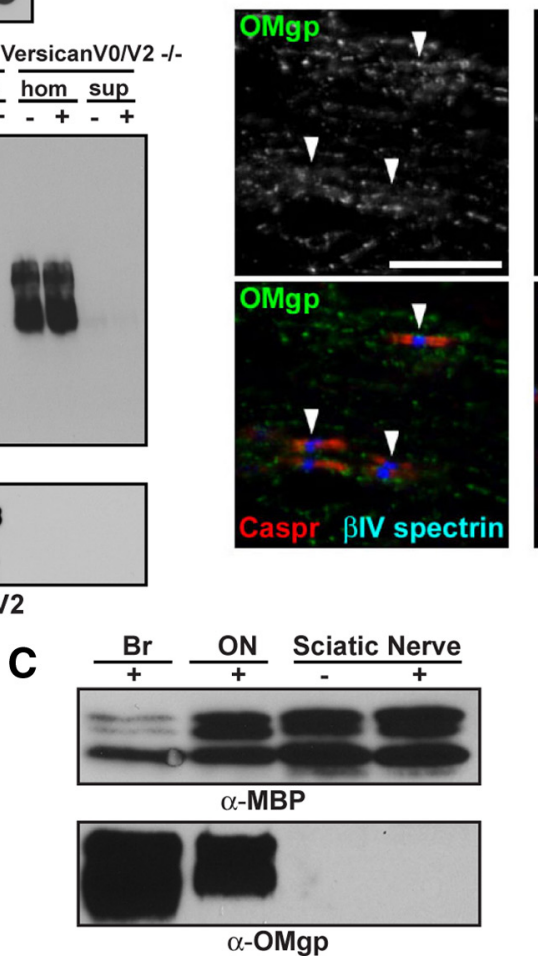
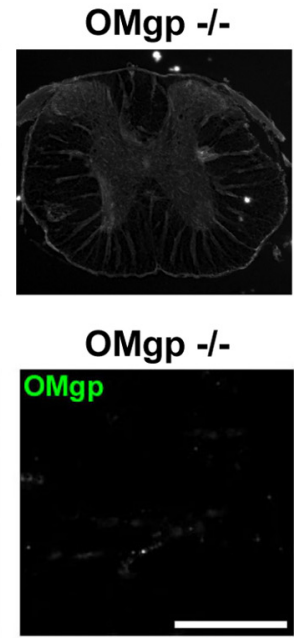

OMgp

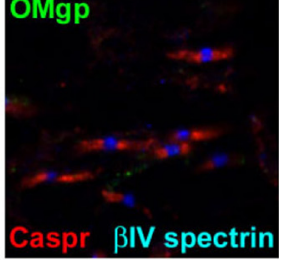

goat anti-mouse OMgp antibody, we did not detect any enrichment of OMgp (Fig. $3 E$ ). These findings indicate that OMgp is expressed in the CNS but is not accumulated at CNS nodes of Ranvier.

In addition to its nodal localization, OMgp was reported previously to be important for proper nodal and paranodal structure, as well as limiting collateral sprouting from CNS nodes. However, our observation that OMgp is not located at nodes prompted us to reexamine CNS nodes and paranodes in OMgp-null mice. We found that OMgpnull tissues showed normal shapes of paranodal Caspr staining (Fig. 3E) in contrast to the diffuse or ectopically clustered pattern previously described (Huang et al., 2005). Furthermore, when we measured nodal length and the axon diameters in optic nerves using immunofluorescence microscopy, we observed no significant difference between wild-type and OMgp-null mice (Fig. 2F), which is also different from what has been reported (Huang et al., 2005; Nie et al., 2006). We found the average nodal lengths to be $0.71 \pm 0.01$ and $0.73 \pm 0.01$ ( $p=0.09$ ) for wild-type and OMgp-null nerves, respectively. The average ratios of nodal length to axon diameter were $1.01 \pm$ 0.02 in wild-type mice and $1.05 \pm 0.02$ in OMgp-null mice $(p=0.11)$. Finally, in both wild-type and OMgp-null optic nerves, we found no axonal sprouting at nodes of Ranvier (Fig. 3E); however, the complexity and heterogeneity of the numerous collaterals in the spinal cord precluded a robust statistical analysis (data not shown). To further confirm our immunostaining results, we performed electron microscopy on optic nerves from wild-type and OMgp-null mice (Fig. 2G). In these experiments, we found node lengths of $0.72 \pm 0.03 \mu \mathrm{m}(n=$ $30)$ and $0.71 \pm 0.03 \mu \mathrm{m}(n=29)$ in the WT and OMgp-null mice, respectively ( \pm SEM, $p=0.81)$. Furthermore, we did not observe a single instance of nodal sprouting in OMgp-

(Fig. 2E). Together, these results demonstrate that previous reports of OMgp at nodes of Ranvier actually detected versican V2.

\section{OMgp is not enriched at CNS nodes, and its absence does not affect paranodes or nodes}

To determine the correct localization of OMgp, we tested three commercially available anti-OMgp antibodies. Among these, only one, a goat anti-mouse OMgp antibody, showed specificity against OMgp (Fig. 3A,B). This antibody strongly immunolabeled wildtype spinal cords, but not OMgp-null tissues (Fig. 3D). In contrast to the CNS, immunostaining of wild-type and OMgp-null sciatic nerves with the anti-OMgp antibody showed only background signals (data not shown). Similarly, Western blot analysis detected no OMgp in sciatic nerve extracts (Fig. 3C), indicating that OMgp is not expressed in the PNS, which is in contrast to previous reports using $\alpha$-OMgp ${ }^{*}$ (Apostolski et al., 1994; Huang et al., 2005). When we closely examined CNS nodes in tissue sections labeled with the null mice. Together, our results support the conclusion that OMgp is not required for the integrity of nodal or paranodal structure.

Although we did not observe any alteration in nodal structure, we nevertheless performed a rotarod test to assay motor function in OMgp-null mice. The average latencies to fall were $150 \pm 14.5 \mathrm{~s}$ and $130 \pm 9.5 \mathrm{~s}$ in OMgp-null $(n=9)$ and wild-type $(n=10)$ mice, respectively. However, these differences were not statistically significant ( \pm SEM, $p=0.28$ ). Importantly, OMgp-null mice also show no defects in open field locomotion, forepaw preference, or grid walk behavioral performance tests (Ji et al., 2008; Lee et al., 2010). These results are consistent with the idea that nodes of Ranvier are intact and function to permit normal action potential conduction.

\section{OMgp is expressed in white matter after the onset of} myelination and localizes outside compact myelin

To determine the localization and temporal expression of OMgp, we immunostained optic nerves during myelination. At postnatal day 6 

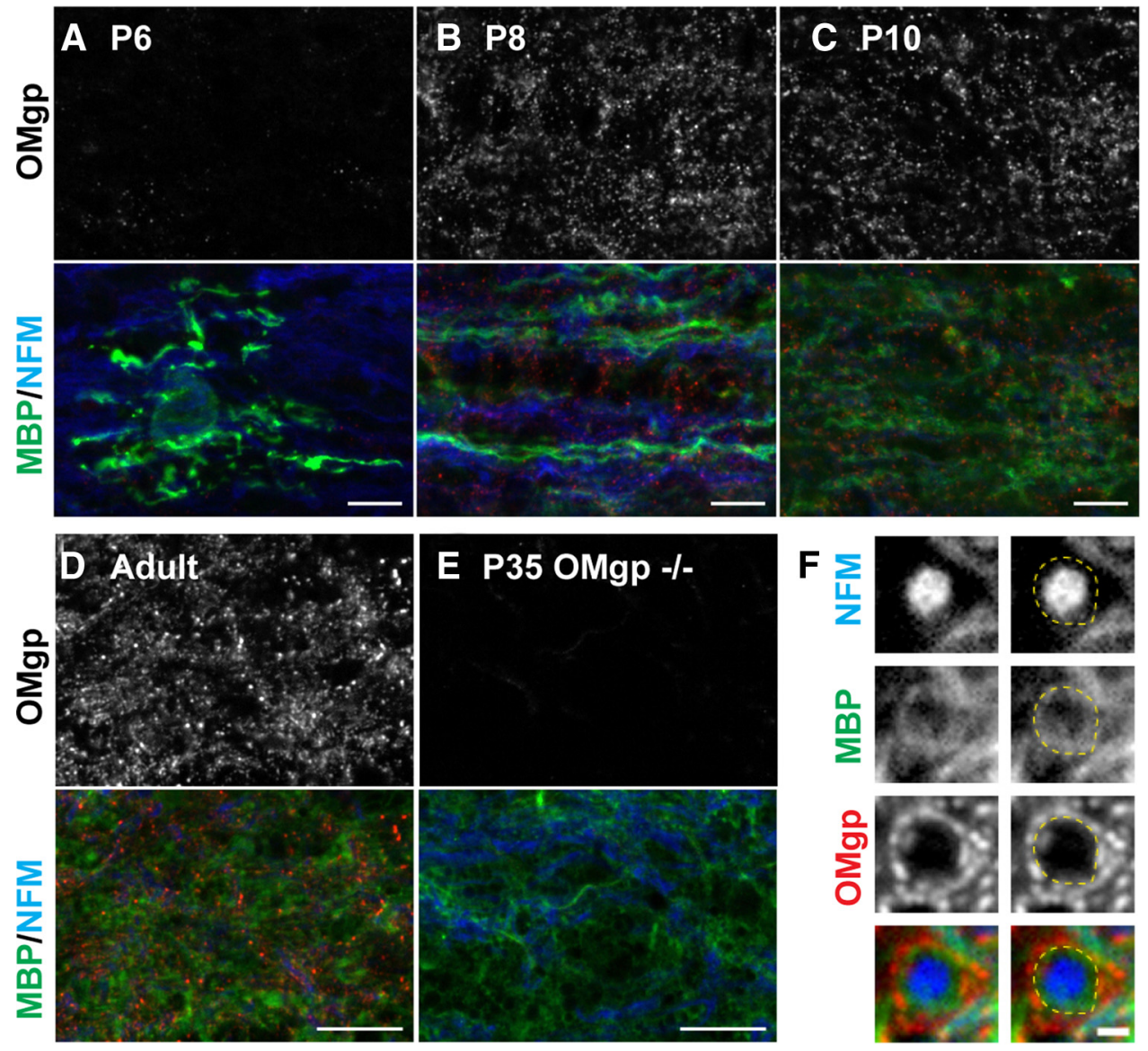

Figure 4. OMgp is expressed during myelination and localizes outside compact myelin. $\boldsymbol{A}-\boldsymbol{E}$, Immunostaining of wild-type $\mathrm{P} 6(\boldsymbol{A}), \mathrm{P} 8(\boldsymbol{B}), \mathrm{P} 10(\boldsymbol{C})$, and adult $(\boldsymbol{D})$ and $0 \mathrm{Mgp}$-null P35 (E) optic nerves using goat anti-0Mgp (red), anti-MBP (green), and anti-neurofilament M (NFM). Scale bars, $10 \mu \mathrm{m}$. $F$, Immunostaining of adult wild-type spinal cord cross sections using goat anti-0Mgp (red), anti-MBP (green), and anti-NFM (blue). The dotted line indicates the outer surface of the compact myelin. Scale bar, $1 \mu \mathrm{m}$.

(P6), very little OMgp staining was observed, and it was not localized to the surface of actively myelinating oligodendrocytes (Fig. 4A). However, in P8, P10, and adult optic nerves, OMgp staining could be detected in a relatively dispersed pattern that did not completely colocalize with MBP (Fig. 4B-D). Finally, when we examined cross sections of spinal cords, we found that OMgp was located outside compact myelin and decorated the surface of myelinated axons (Fig. $4 F$ ).

\section{Discussion}

Two previous studies reported that OMgp is localized at nodes of Ranvier in both the CNS and PNS and concluded that it plays distinct roles in formation and stabilization of CNS nodes (Huang et al., 2005; Nie et al., 2006). However, the data presented here strongly argue against a role for OMgp at nodes. In both previous reports, nodal OMgp localization was shown by immunostaining using $\alpha$-OMgp ${ }^{\star}$. We showed that $\alpha$-OMgp ${ }^{\star}$ strongly reacts with versican V2 but only weakly with OMgp. Nodal staining by $\alpha$-OMgp ${ }^{\star}$ was produced by its reactivity against versican V2, but not OMgp. This was clearly shown by (1) immunostaining of mutant tissues, (2) immunoadsorption tests, and (3) a specific anti-OMgp antibody, which did not label nodes.

$\alpha$-OMgp ${ }^{\star}$ was originally generated using OMgp isolated from human CNS tissues through phospholipase $\mathrm{C}$ treatment and PNA affinity chromatography, which purifies $\mathrm{Gal}(\beta 1-3)$ GalNAc residue-bearing glycoproteins (Mikol and Stefansson, 1988; Mikol et al., 1990). It is unlikely that the cross-reactivity can be explained simply by a common epitope found in both versican and OMgp, since preadsorption of $\alpha$-OMgp ${ }^{*}$ with OMgp-Fc fusion proteins did not block nodal labeling. In a different study, purification of PNA-binding glycoproteins from spinal cords identified OMgp and the N-terminal fragment of versican (Apostolski et al., 1994). Furthermore, all the proteoglycan isoforms of versican interact with PNA (Dutt et al., 2006). Therefore, it is likely that the original purification of OMgp by phospholipase $\mathrm{C}$ treatment and PNA affinity purification resulted in copurification of versican. Chondroitinase treatment is required to detect the majority of full-length versican bearing chondroitin sulfate side chains in SDS-PAGE (Schmalfeldt et al., 1998). Even the core glycoprotein of versican V2 migrates at an apparent molecular weight of $\sim 400,000$. Thus, if full-length versican had been copurified, it might have evaded detection when the purity of OMgp was assessed. The results presented here should serve as a cautionary tale when using antibodies and emphasize the need for careful and appropriate control experiments (Rhodes and Trimmer, 2006).

Previous reports indicated that OMgp-null and OMgp mutant mice have nodal and paranodal defects (Huang et al., 2005; Nie et al., 2006). Since node of Ranvier formation depends on myelination and neuron-glia interactions, it is possible that the nodal defects were due to altered myelination or disrupted paranodal junctions, rather than the absence of OMgp at nodes. However, we were unable to detect any nodal or paranodal abnormalities by both immunofluorescence and electron microscopy, suggesting that myelination and 
neuron-glia interactions are normal in OMgp-null mice. Furthermore, OMgp-null mice have a normal lifespan and no apparent behavioral abnormalities: they have normal gaits and are fecund [data not shown and Ji et al. (2008)]. Disruptions in myelination, node, or paranode assembly would be expected to cause an overt behavioral phenotype, similar to the paranodal or dysmyelinating mutants previously described (Poliak and Peles, 2003).

This work not only revealed the nonspecific cross-reactivity of $\alpha$-OMgp ${ }^{\star}$, but also showed the correct expression and localization of OMgp in white matter by using a specific antibody. We found that OMgp does not localize to the surface of myelinating oligodendrocytes at the early onset of myelination in optic nerves, but instead increases with myelination. In adult mice, OMgp localizes outside compact myelin and surrounds myelinated axons, suggesting that OMgp is not a compact myelin component, which is consistent with early biochemical observations (Mikol and Stefansson, 1988). However, our results do not show whether OMgp is expressed as a GPI-anchored form on the glial membrane or is released from the GPI moiety (from neurons or glia) and then becomes associated with the glial membrane. While the form of OMgp released from its GPI moiety has been observed in tissue homogenates and oligodendrocyte cultures (Mikol and Stefansson, 1988; Nie et al., 2006; Gil et al., 2010) (Fig. 3B), the exact functional significance remains obscure. This same antibody was also used in a recent study describing the expression and distribution of OMgp in different regions of the developing mouse telencephalon (Gil et al., 2010). Rather than a role in myelination, these authors found that thalamocortical axons innervating the barrel cortex of OMgp-null mice are much less restricted to layer IV cortical neurons. Thus, OMgp may play roles in restricting appropriate axon targeting in the developing cortex.

In conclusion, contrary to previous reports, we have shown here that OMgp is not expressed in the PNS, OMgp is not a component of the CNS nodal ECM, OMgp is not essential for node or paranode structure, and OMgp is not a compact myelin protein. Although OMgp's role in injury and nervous system regeneration has been demonstrated (Atwal et al., 2008; Giger et al., 2008; Ji et al., 2008), the findings presented here show that much work remains to be done to understand the normal function of OMgp in the CNS.

\section{References}

Apostolski S, Sadiq SA, Hays A, Corbo M, Suturkova-Milosevic L, Chaliff P, Stefansson K, LeBaron RG, Ruoslahti E, Hays AP, Latov N (1994) Identification of $\mathrm{Gal}(\beta 1-3)$ GalNAc bearing glycoproteins at the nodes of Ranvier in peripheral nerve. J Neurosci Res 38:134-141.

Atwal JK, Pinkston-Gosse J, Syken J, Stawicki S, Wu Y, Shatz C, TessierLavigne M (2008) PirB is a functional receptor for myelin inhibitors of axonal regeneration. Science 322:967-970.

Bartsch U, Pesheva P, Raff M, Schachner M (1993) Expression of janusin (J1-160/180) in the retina and optic nerve of the developing and adult mouse. Glia 9:57-69.

Bekku Y, Vargová L, Goto Y, Vorísek I, Dmytrenko L, Narasaki M, Ohtsuka A, Fässler R, Ninomiya Y, Syková E, Oohashi T (2010) Brall: its role in diffusion barrier formation and conduction velocity in the CNS. J Neurosci 30:3113-3123.

Berghs S, Aggujaro D, Dirkx R Jr, Maksimova E, Stabach P, Hermel JM, Zhang JP, Philbrick W, Slepnev V, Ort T, Solimena M (2000) betaIV spectrin, a new spectrin localized at axon initial segments and nodes of Ranvier in the central and peripheral nervous system. J Cell Biol 151:985-1002.

Dours-Zimmermann MT, Maurer K, Rauch U, Stoffel W, Fässler R, Zimmermann DR (2009) Versican V2 assembles the extracellular matrix surrounding the nodes of Ranvier in the CNS. J Neurosci 29:7731-7742.

Dutt S, Kléber M, Matasci M, Sommer L, Zimmermann DR (2006) Versican V0 and V1 guide migratory neural crest cells. J Biol Chem 281:12123-12131.

Eshed Y, Feinberg K, Carey DJ, Peles E (2007) Secreted gliomedin is a perinodal matrix component of peripheral nerves. J Cell Biol 177:551-562.
Giger RJ, Venkatesh K, Chivatakarn O, Raiker SJ, Robak L, Hofer T, Lee H, Rader C (2008) Mechanisms of CNS myelin inhibition: evidence for distinct and neuronal cell type specific receptor systems. Restor Neurol Neurosci 26:97-115.

Gil V, Bichler Z, Lee JK, Seira O, Llorens F, Bribian A, Morales R, ClaverolTinture E, Soriano E, Sumoy L, Zheng B, Del Río JA (2010) Developmental expression of the oligodendrocyte myelin glycoprotein in the mouse telencephalon. Cereb Cortex 20:1769-1779.

Habib AA, Marton LS, Allwardt B, Gulcher JR, Mikol DD, Högnason T, Chattopadhyay N, Stefansson K (1998) Expression of the oligodendrocyte-myelin glycoprotein by neurons in the mouse central nervous system. J Neurochem 70:1704-1711.

Hedstrom KL, Xu X, Ogawa Y, Frischknecht R, Seidenbecher CI, Shrager P, Rasband MN (2007) Neurofascin assembles a specialized extracellular matrix at the axon initial segment. J Cell Biol 178:875-886.

Huang JK, Phillips GR, Roth AD, Pedraza L, Shan W, Belkaid W, Mi S, Fex-Svenningsen A, Florens L, Yates JR 3rd, Colman DR (2005) Glial membranes at the node of Ranvier prevent neurite outgrowth. Science 310:1813-1817.

Ji B, Case LC, Liu K, Shao Z, Lee X, Yang Z, Wang J, Tian T, Shulga-Morskaya S, Scott M, He Z, Relton JK, Mi S (2008) Assessment of functional recovery and axonal sprouting in oligodendrocyte-myelin glycoprotein (OMgp) null mice after spinal cord injury. Mol Cell Neurosci 39:258-267.

Kaplan MR, Meyer-Franke A, Lambert S, Bennett V, Duncan ID, Levinson SR, Barres BA (1997) Induction of sodium channel clustering by oligodendrocytes. Nature 386:724-728.

Lee JK, Geoffroy CG, Chan AF, Tolentino KE, Crawford MJ, Leal MA, Kang B, Zheng B (2010) Assessing spinal axon regeneration and sprouting in Nogo-, MAG-, and OMgp-deficient mice. Neuron 66:663-670.

Mikol DD, Stefansson K (1988) A phosphatidylinositol-linked peanut agglutinin-binding glycoprotein in central nervous system myelin and on oligodendrocytes. J Cell Biol 106:1273-1279.

Mikol DD, Gulcher JR, Stefansson K (1990) The oligodendrocyte-myelin glycoprotein belongs to a distinct family of proteins and contains the HNK-1 carbohydrate. J Cell Biol 110:471-479.

Nie DY, Ma QH, Law JW, Chia CP, Dhingra NK, Shimoda Y, Yang WL, Gong N, Chen QW, Xu G, Hu QD, Chow PK, Ng YK, Ling EA, Watanabe K, Xu TL, Habib AA, Schachner M, Xiao ZC (2006) Oligodendrocytes regulate formation of nodes of Ranvier via the recognition molecule OMgp. Neuron Glia Biol 2:151-164.

Oohashi T, Hirakawa S, Bekku Y, Rauch U, Zimmermann DR, Su WD, Ohtsuka A, Murakami T, Ninomiya Y (2002) Bral1, a brain-specific link protein, colocalizing with the versican V2 isoform at the nodes of Ranvier in developing and adult mouse central nervous systems. Mol Cell Neurosci 19:43-57.

Poliak S, Peles E (2003) The local differentiation of myelinated axons at nodes of Ranvier. Nat Rev Neurosci 4:968-980.

Rasband MN, Peles E, Trimmer JS, Levinson SR, Lux SE, Shrager P (1999) Dependence of nodal sodium channel clustering on paranodal axoglial contact in the developing CNS. J Neurosci 19:7516-7528.

Rhodes KJ, Trimmer JS (2006) Antibodies as valuable neuroscience research tools versus reagents of mass distraction. J Neurosci 26:8017-8020.

Salzer JL (2003) Polarized domains of myelinated axons. Neuron 40:297-318.

Schafer DP, Bansal R, Hedstrom KL, Pfeiffer SE, Rasband MN (2004) Does paranode formation and maintenance require partitioning of neurofascin 155 into lipid rafts? J Neurosci 24:3176-3185.

Schmalfeldt M, Dours-Zimmermann MT, Winterhalter KH, Zimmermann DR (1998) Versican V2 is a major extracellular matrix component of the mature bovine brain. J Biol Chem 273:15758-15764.

Susuki K, Rasband MN (2008) Molecular mechanisms of node of Ranvier formation. Curr Opin Cell Biol 20:616-623.

Vourc'h P, Andres C (2004) Oligodendrocyte myelin glycoprotein (OMgp): evolution, structure and function. Brain Res Brain Res Rev 45:115-124.

Xiao ZC, Bartsch U, Margolis RK, Rougon G, Montag D, Schachner M (1997) Isolation of a tenascin-R binding protein from mouse brain membranes. A phosphacan-related chondroitin sulfate proteoglycan. J Biol Chem 272:32092-32101.

Yamaguchi Y (2000) Lecticans: organizers of the brain extracellular matrix. Cell Mol Life Sci 57:276-289.

Zimmermann DR, Dours-Zimmermann MT (2008) Extracellular matrix of the central nervous system: from neglect to challenge. Histochem Cell Biol 130:635-653. 